\title{
Psychosocial work characteristics and self rated health in four post-communist countries
}

H Pikhart, M Bobak, J Siegrist, A Pajak, S Rywik, J Kyshegyi, A Gostautas, Z Skodova, M Marmot

Abstract

Study objectives-To examine whether psychosocial factors at work are related to self rated health in post-communist countries.

Design and settings-Random samples of men and women in five communities in four countries were sent a postal questionnaire (Poland, Czech Republic and Lithuania) or were invited to an interview (Hungary). Working subjects $(n=3941)$ reported their self rated health in the past 12 months (5 point scale), their socioeconomic circumstances, perceived control over life, and the following aspects of the psychosocial work environment: job control, job demand, job variety, social support, and effort and reward at work (to calculate a ratio of effort/reward imbalance). As the results did not differ by country, pooled analyses were performed. Odds ratios of poor or very poor health ("poor health") were estimated for a $1 \mathrm{SD}$ increase in the scores of work related factors.

Main results-The overall prevalence of poor health was $6 \%$ in men and $7 \%$ in women. After controlling for age, sex and community, all work related factors were associated with poor health $(p<0.05)$. After further adjustment for perceived control, only two work related factors remained associated with poor health; the odds ratios (95\% confidence intervals) for $1 \mathrm{SD}$ increase in the effort/reward ratio (log transformed) and job variety were $1.51(1.29,1.78)$ and $0.82(0.73,1.00)$, respectively. Further adjustment for all work related factors did not change these estimates. There were no interactions between individual work related factors, but the effects of job control and social support at work differed by marital status, and the odds ratio of job demand increased with increasing education.

Conclusions-The continuous measure of effort/reward imbalance at work was a powerful determinant of self rated health in these post-communist populations. Although the cross sectional design does not allow firm conclusions as to causality, this study suggests that the effect of the psychosocial work environment is not confined to Western populations.

(F Epidemiol Community Health 2001;55:624-630)

London, 1-19 Torrington

Place, London WC1E 6BT,

UK

(hynek@public-health.ucl.ac.uk)

Accepted for publication

18 January 2001
Self rated health is an important outcome for socioepidemiological research. Firstly, level of wellbeing and perceived health influence a person's quality of everyday life, including the motivation to engage in social activities or to stay away from work. Secondly, in an impressive number of prospective investigations poor self rated health was found to increase the risk of mortality, even after controlling for confounders such as age, gender, socioeconomic status, and "objective" health conditions as evidenced by medical records. ${ }^{1-5}$

Several investigations have shown that self rated health varies according to socioeconomic and psychosocial conditions, such as socioeconomic position, ${ }^{6}$ material deprivation, ${ }^{7}$ gender, ${ }^{8}$ level of social support, ${ }^{9}$ and degree of general control in life. ${ }^{71} 11^{11}$ The quality of working life has received surprisingly little attention in these investigations despite its importance for economic, social and psychological wellbeing. ${ }^{12}$ In particular, this is true for the psychosocial work environment that has far reaching impact on mood, motivation, mental and physical health. ${ }^{13-15}$

In this paper, we tested the hypothesis that the psychosocial work environment has an effect on self rated health in economically active populations, and that the associations between psychosocial work environment and self rated health remain statistically significant after controlling for the above mentioned socioeconomic and psychosocial conditions. The study is carried out in economically active population samples from four countries in Central and Eastern Europe. As with all post-communist societies, these countries underwent a rapid and profound social change in the recent past. ${ }^{16-18}$

Psychosocial work environment was conceptualised in terms of two alternative theoretical models. Firstly, we tested the model of job demand, job control and support at work developed by Karasek, Theorell and Johnson. ${ }^{14} 1920$ This model focuses on stressful job task characteristics in terms of a combination of high psychological demand, low social support and low decision latitude or low degree of job variety. The second model tested in this study was the model of effort-reward imbalance developed by Siegrist. ${ }^{1521}$ This concept emphasises the imbalance between high effort at work and low reward received in turn, where rewards concern money, esteem and career opportunities, including job security. Thus, this model considers the impact of selected labour market conditions (level of salary, career opportunities, job instability and unemployment) on health in addition to the more proximal job conditions. Both models have been 
shown to predict physical and mental health in a number of prospective and cross sectional epidemiological investigations, ${ }^{22}{ }^{23}$ and recent comparative studies revealed their independent effects on health. ${ }^{24}{ }^{25}$ Based on this evidence, the present study includes both models to test the associations of psychosocial work environment and self rated health.

\section{Methods}

POPULATIONS AND SAMPLES

This was a cross sectional study in five population samples in four countries of Central and Eastern Europe. Four samples were based on populations participating in the WHO MONICA Project ${ }^{26}$ : six districts of the Czech Republic; Warsaw and Tarnobrzeg, Poland; and Kaunas, Lithuania. The remaining sample consisted of a baseline survey for a prevention programme in the town of Kalocsa, Hungary. All samples were chosen randomly from population registers, all surveys were conducted between 1995 and 1996. Data were collected by postal questionnaires (all MONICA samples) and by an interview (Hungary). Completed questionnaires were received from 6642 subjects, and response rates were $73 \%$ in Lithuania, $75 \%$ in the Czech Republic, $72 \%$ in Warsaw, $76 \%$ in Tarnobrzeg, and $94 \%$ in Hungary. The analyses of work related factors was restricted to 3941 working subjects.

SELF REPORTED HEALTH

Self rated health was assessed by the question "How would you rate your health in the last 12 months?", with five possible answers: "very good", "good", "average", "bad" and "very bad". For the present analyses, these responses were dichotomised into two categories, with participants reporting "bad" or "very bad" health classified as "poor health". The question "Have you ever had heart trouble suspected or confirmed by a doctor" was used as a proxy measure for history of coronary heart disease.

PSYCHOSOCIAL FACTORS AT WORK

Six characteristics of the psychosocial environment at work were measured: decision authority (four questions), job demand (one question), job variety (four questions), social support at work (for questions), and effort and reward at work (6 and 11 questions, respectively). The questions are shown in the appendix. In addition, decision authority and job variety were combined into a single variable of job control. ${ }^{27}$ Internal consistency of the scores defined above was assessed by Cronbach's $\alpha$; it ranged from 0.74 to 0.81 .

For decision authority, job demand, job variety and social support at work, responses were given at a 4 point scale. The answers were coded to values 0 to 3 , and average scores were calculated. For decision authority, job variety and social support at work, the average score was calculated if at least three questions had valid data. Responses to questions on effort and reward were coded to values 1 or 2 , and average scores were calculated if a minimum of five and nine questions, respectively, contained valid answers. The effort/reward ratio was estimated as a continuous measure (the ratio of the respective scores) in order to improve the statistical power of this construct. The continuous ratio was logarithmically transformed in order to place inverse imbalance of the same magnitude (for example 0.5 and 2) in the same distance from 1 (when effort and reward are equal). Job strain was defined as the combination of low/high job demand and job control.

\section{ADDITIONAL VARIABLES}

Information was collected on a range of other factors known to influence self rated health. Subjects were classified into four categories of attained education: primary or less, vocational (apprenticeship), secondary (A level equivalent), and university degree. An indicator of material deprivation was assessed by three questions about how often the subject's household had difficulties to buy enough food or clothes and to pay bills for housing, heating and electricity. The possible answers were "never or almost never", "sometimes", "often" and "always". These responses were coded as 0,1 , 2 or 3 , and a deprivation score was calculated as the sum. Occupation position was classified into three crude categories: "managerial/ supervisor", "other employee", and "self employed". Study subjects were categorised by marital status as "married" and "unmarried" people (more detailed information was not available). We have also constructed a score of "perceived general control" calculated from nine questions, adapted from the Whitehall II Study and by the MacArthur Study on Successful Midlife, as described elsewhere. ${ }^{18}{ }^{28}$

\section{STATISTICAL ANALYSIS}

Data were first cross tabulated by centre (country), and descriptive measures were calculated. Associations between self rated health and work characteristics were estimated by logistic regression. The associations were similar across populations; data were therefore pooled, and the overall results are reported. Because all psychosocial factors at work were measured on a continuous scale, the odds ratios are reported for an increase by 1 standard deviation. Thus, the effects of different variables on self rated health can be directly compared in quantitative terms. The association between self rated health and psychosocial work characteristics was analysed in several steps. Firstly, the odds ratios were adjusted for age, gender, and population. In a second step, odds ratios were further adjusted for history of coronary heart disease, type of employment, education, deprivation and marital status. Thirdly, perceived general control was added to the model. Finally, all psychosocial work characteristics and covariates were entered into the model. Throughout the analyses, we have tested for interactions (in multiplicative models) among different psychosocial factors at work and between psychosocial and socioeconomic variables. All analyses were performed using STATA statistical software (Stata Corporation, College Station, USA). 


\section{Results}

Of 3941 working subjects who completed a questionnaire, 2846 had valid (non-missing) data on self rated health, all work characteristics and all covariates. These subjects, the basis of the subsequent analyses, are described in table 1. Distributions of main variables were similar in men and women and in the five populations (not shown). The fact that urban populations were overrepresented is the probable reason for the relatively high proportion of subjects with higher education. As expected in a population of this age the overall prevalence of poor or very poor self rated health was low. In the lower part of table 1 , the means and standard deviations of work related psychosocial characteristics in the study population are presented. Effort and reward did not differ between men and women, but job demand was

Table 1 Descriptive characteristics of the subjects included in the analysis

\begin{tabular}{|c|c|c|c|}
\hline & $\begin{array}{l}\text { Men } \\
\text { Number (\%) }\end{array}$ & $\begin{array}{l}\text { Women } \\
\text { Number (\%) }\end{array}$ & $\begin{array}{l}\text { expected direction. Poor health was more com- } \\
\text { mon in the group characterised by high }\end{array}$ \\
\hline \multicolumn{4}{|r|}{ trol. As the effects of job } \\
\hline Poland (Warsaw) & $173(11.8)$ & $161(11.6)$ & demand and job control were independent \\
\hline Poland (Tarnobrzeg) & $187(12.8)$ & $199(14.4)$ & \multirow{2}{*}{ from each other, and there was no interaction } \\
\hline Lithuania & $220(15.1)$ & $201(14.5)$ & \\
\hline Czech Republic & $526(36.0)$ & $461(33.3)$ & between them $(p=0.90)$, they were used \\
\hline Hungary & $356(24.4)$ & $362(26.2)$ & separately in subsequent analyses. \\
\hline $\begin{array}{l}\text { Self rated health } \\
\text { very good }\end{array}$ & $101(6.9)$ & $71(5.1)$ & In previous studies of effort-reward imbal- \\
\hline good & $666(45.6)$ & $541(39.1)$ & ance, the exposure was defined as effort/reward \\
\hline average & $609(41.7)$ & $673(48.6)$ & \multirow{2}{*}{ ratio being larger than 1 . Because only $10 \%$ of } \\
\hline poor & $84(5.8)$ & $94(6.8)$ & \\
\hline very poor & $2(0.1)$ & $5(0.4)$ & \\
\hline Age & & & \multirow{4}{*}{$\begin{array}{l}\text { Table } 2 \text { Age, sex and centre adjusted odds ratios (OR and } \\
95 \% \text { CI) of poor self rated health by psychosocial work } \\
\text { characteristics and additional explanatory variables }\end{array}$} \\
\hline $20-34$ & $233(15.9)$ & $218(15.8)$ & \\
\hline $35-44$ & $493(33.7)$ & $538(38.9)$ & \\
\hline $45-54$ & $511(35.0)$ & $489(35.3)$ & \\
\hline$\stackrel{55+}{5}$ & $225(15.4)$ & $139(10.0)$ & \multirow{2}{*}{$\begin{array}{l}\text { Adjusted for age, } \\
\text { sex and centre }\end{array}$} \\
\hline $\begin{array}{r}\text { Education } \\
\text { Primary }\end{array}$ & $169(11.6)$ & $221(16.0)$ & \\
\hline Vocational & $408(27.9)$ & $396(28.6)$ & Job demand \\
\hline Secondary & $555(38.0)$ & $506(36.6)$ & $\begin{array}{l}\text { Job demand } \\
\text { per } 1 S D\end{array}$ \\
\hline University & $330(22.6)$ & $261(18.9)$ & $\begin{array}{l}\text { per } 1 \text { SD } \\
\text { Decision authority }\end{array}$ \\
\hline Material deprivation & & & $\begin{array}{l}\text { Decision authority } \\
\text { per } 1 \mathrm{SD}\end{array}$ \\
\hline Low $(0-4.9)$ & $1069(73.1)$ & $926(66.9)$ & Job variety \\
\hline $\begin{array}{l}\text { High }(5-10) \\
\text { Employment category }\end{array}$ & $393(26.9)$ & $458(33.1)$ & $0.75(0.65,0.87)$ \\
\hline $\begin{array}{l}\text { Employment category } \\
\text { Manager/supervisor }\end{array}$ & $293(20.0)$ & $206(14.9)$ & Job control* ${ }^{*}$ \\
\hline Other employee & $779(53.3)$ & $774(55.9)$ & $0.74(0.64,0.86)$ \\
\hline Self employed & $379(25.9)$ & $388(28.0)$ & Job strain \\
\hline Not specified & $11(0.8)$ & $16(1.2)$ & Low demand-low c \\
\hline Marital status & & & Low demand-high control \\
\hline Married & $1267(86.7)$ & $1085(78.4)$ & High demand-low control \\
\hline Unmarried & $195(13.3)$ & $299(21.6)$ & $0.79(0.51,1.22)$ \\
\hline Range & Mean (SD) & Mean (SD) & Social support \\
\hline Decision authority & & & $0.82(0.70,0.96)$ \\
\hline 0 (low), 3 (high) & $2.03(0.83)$ & $1.91(0.88)$ & $\log ($ effort/reward) \\
\hline Job demand & & & $1.75(1.52,2.02)$ \\
\hline 0 (low), 3 (high) & $2.32(0.73)$ & $2.44(0.71)$ & Education \\
\hline Job strain, number (\%) & & & Primary \\
\hline Low demand-low decision & $416(28.5)$ & $391(28.3)$ & $0.64(0.41,1.01)$ \\
\hline control & & & $0.46(0.29,0.73)$ \\
\hline $\begin{array}{l}\text { Low demand-high decision } \\
\text { control }\end{array}$ & $371(25.4)$ & $236(17.1)$ & $\begin{array}{l}0.29(0.17,0.50) \\
<0.001\end{array}$ \\
\hline High demand-low decision & $296(20.3)$ & $395(28.5)$ & Marital status \\
\hline control & & & Married \\
\hline High demand-high decision & $379(25.9)$ & $362(26.2)$ & $\begin{array}{l}\text { Unmarried } \\
\text { Deprivation }\end{array}$ \\
\hline $\begin{array}{l}\text { contr } \\
\text { Effort }\end{array}$ & & & $\begin{array}{l}\text { Deprivation } \\
\text { per } 1 \text { SD }\end{array}$ \\
\hline 1 (low), 2 (high) & $1.23(0.27)$ & $1.24(0.29)$ & Employment status \\
\hline Reward & & & Manager/supervisor \\
\hline 1 (low), 2 (high) & $1.16(0.21)$ & $1.17(0.21)$ & $1.09(0.71,1.68)$ \\
\hline $\log (\mathrm{E} / \mathrm{R}$ ratio) & & & $1.12(0.70,1.80)$ \\
\hline$-0.69,0.61$ & $-0.41(0.27)$ & $-0.40(0.29)$ & Perceived control \\
\hline Support at work & & & $0.51(0.43,0.61)$ \\
\hline 0 (low), 3 (high) & $2.05(0.78)$ & $2.10(0.76)$ & Self reported CVD \\
\hline Job variety & & & no \\
\hline 0 (low), 3 (high) & $2.18(0.69)$ & $1.99(0.77)$ & $2.78(2.03,3.83)$ \\
\hline Job control & & & \\
\hline 0 (low), 3 (high) & $2.11(0.65)$ & $1.95(0.70)$ & nation of decision authority and \\
\hline
\end{tabular}

higher and work variety and decision authority lower among women.

The correlations between the psychosocial and socioeconomic factors were weak, with the exception of the correlation between decision authority and job variety $(r=0.44)$. This strong association is justified by the fact that the two constructs overlap at the conceptual and measurement level. Deprivation and job control were negatively associated $(r=-0.35)$, and job variety and education were positively correlated $(r=0.30)$.

The associations between self rated health, psychosocial work factors and socioeconomic variables adjusted for age, gender, and population, are shown in table 2. Poor (bad or very bad) self rated health was related to education, perceived general control in life, self reported cardiovascular disease, and all five psychosocial job characteristics. The effects were strongest for educational level, perceived control, self reported cardiovascular disease, and effortreward imbalance. All associations were in the demand and low control. As the effects of job demand and job control were independent from each other, and there was no interaction eparately in subsequent analyses.

In previous studies of effort-reward imbalance, the exposure was defined as effort/reward

Table 2 Age, sex and centre adjusted odds ratios (OR and 95\% CI) of poor self rated health by psychosocial work characteristics and additional explanatory variables 
Table 3 Odds ratios (OR and 95\% CI) of poor self rated health by work related psychosocial work characteristics

\begin{tabular}{llll}
\hline & Adjustment 1 & Adjustment 2 & Adjustment 3 \\
\hline Job demand & $1.11(0.94,1.11)$ & $1.09(0.92,1.29)$ & $1.03(0.86,1.23)^{\mathrm{a}}$ \\
Decision authority & $0.85(0.73,1.00)$ & $0.91(0.77,1.07)$ & $0.98(0.82,1.18)^{\mathrm{a}}$ \\
Job variety & $0.82(0.70,0.97)$ & $0.85(0.73,1.00)$ & $0.83(0.69,1.01)^{\mathrm{a}}$ \\
Job control & $0.81(0.69,0.95)$ & $0.86(0.73,1.02)$ & $0.86(0.72,1.02)^{\mathrm{b}}$ \\
Social support & $0.87(0.74,1.02)$ & $0.91(0.77,1.07)$ & $1.04(0.87,1.25)^{\mathrm{a}}$ \\
Log (effort/reward) & $1.60(1.38,1.86)$ & $1.51(1.30,1.76)$ & $1.51(1.29,1.78)^{\mathrm{a}}$ \\
\hline
\end{tabular}

${ }^{\star}$ Job control combines decision authority and job variety. Adjustment 1: age, sex, population, history of cardiovascular disease, type of employment, education, deprivation, marital status. Adjustment 2: age, sex, population, history of cardiovascular disease, type of employment, education, deprivation, marital status, perceived control. Adjustment 3: a: age, sex, population, history of cardiovascular disease, type of employment, education, deprivation, marital status, perceived control, all remaining work characteristics except job control. b: age, sex, population, history of cardiovascular disease, type of employment, education, deprivation, marital status, perceived control, job demand, social support, effort-reward imbalance.

working subjects fulfilled this definition, we examined whether the binary measured imbalance could be replaced by a continuous measure. The age-sex adjusted odds ratios for the binary measure of effort/reward imbalance was $2.65(95 \%$ CI $1.78,3.95)$. When subjects were grouped into quintiles of the effort-reward ratio, the odds ratios ( $95 \% \mathrm{CI}$ ) for the 2 nd to 5 th quintiles, compared with the first quintile, were $0.93(0.49,1.74), 2.53(1.50,4.27), 3.84$ $(2.32,6.36), 4.06(2.43,6.79)$. This, as well as further analyses (not shown), suggest a linear relation. Another indicator of how well the data explain the dependent variable is the change in the log likelihood after including an independent variable into a model (and is equivalent to the $\chi^{2}$ test at 1 degree of freedom). The $\chi^{2}$ was 26.0 after including the continuous measure of effort reward-imbalance, compared with 7.4 after including the binary measure. This clearly confirms that the binary measure (which would compare the top $10 \%$ with the remaining $90 \%$ of subjects) is inferior to the continuous measure in this study.

Table 3 provides the results of the main analyses. The odds ratios, adjusted for age, gender, population, history of cardiovascular disease, type of employment, education, deprivation, and marital status, were statistically significant for decision authority, job variety, and effort-reward imbalance. After further adjustment for "perceived control over life", the effort-reward imbalance and, with borderline significance, job variety, remained associated with poor health. With all job characteristics in one model (adjustment 3), effort-reward imbalance at work remained the most powerful

Table 4 Odds ratios of psychosocial work characteristics according to different levels of socioeconomic/sociodemographic factors

\begin{tabular}{|c|c|c|c|c|c|c|}
\hline & $\begin{array}{l}\log \\
(E / R)\end{array}$ & $\begin{array}{l}\text { Decision } \\
\text { authority }\end{array}$ & $\begin{array}{l}\text { fob } \\
\text { demand }\end{array}$ & $\begin{array}{l}\text { Work } \\
\text { support }\end{array}$ & $\begin{array}{l}\text { fob } \\
\text { variety }\end{array}$ & $\begin{array}{l}\text { fob } \\
\text { control* }\end{array}$ \\
\hline \multicolumn{7}{|l|}{ Education } \\
\hline primary & 1.73 & 1.01 & 0.82 & 0.69 & 0.86 & 0.92 \\
\hline vocational & 1.57 & 0.95 & 1.13 & 0.94 & 0.78 & 0.85 \\
\hline secondary & 1.68 & 0.77 & 1.35 & 0.85 & 0.79 & 0.73 \\
\hline university & 2.42 & 0.82 & 2.38 & 0.95 & 1.11 & 0.92 \\
\hline test for interaction & NS & NS & $\mathrm{p}<0.01$ & NS & NS & NS \\
\hline \multicolumn{7}{|l|}{ Deprivation } \\
\hline low $(0-4.9)$ & 1.73 & 0.76 & 1.04 & 0.82 & 0.73 & 0.73 \\
\hline high $(5-10)$ & 1.63 & 0.89 & 1.25 & 0.88 & 0.81 & 0.80 \\
\hline test for interaction & NS & NS & NS & NS & NS & NS \\
\hline \multicolumn{7}{|l|}{ Marital status } \\
\hline married & 1.78 & 0.72 & 1.18 & 0.74 & 0.70 & 0.67 \\
\hline unmarried & 1.85 & 1.34 & 1.15 & 1.32 & 0.97 & 1.14 \\
\hline test for interaction & NS & $\mathrm{p}<0.01$ & NS & $\mathrm{p}<0.05$ & NS & $\mathrm{p}<0.05$ \\
\hline
\end{tabular}

NS: $p>0.10 .{ }^{\star}$ Job control is the combination of decision authority and job variety.
KEY POINTS

- Psychosocial work characteristics were related to self rated health in population samples of working men and women in four post-communist countries.

- The continuous measure of the imbalance of effort and reward at work seemed to have the largest effect.

- Among job strain model variables, low job variety was the most strongly associated with poor health.

- Education, material deprivation and perceived control over life were also strongly associated with self rated health in these populations.

predictor of the outcome. Job variety and job control (combining job variety and decision authority) were marginally significantly associated with poor self rated health.

In additional analyses we explored whether the effects of work related psychosocial factors on self rated health varied by socioeconomic circumstances. To do so, the odds ratios for the psychosocial factors at work were estimated within each stratum of education, material deprivation, and marital status (table 4). We found only two statistically significant interactions: the effect of high work demand on poor health was stronger among the better educated. Decision authority and social support were related to reduced risk of poor health in married, but not in unmarried, subjects.

\section{Discussion}

This study found consistent associations of education, perceived general control and selected psychosocial work characteristics with self reported health in five population samples from Central and Eastern Europe. In particular, there was a strong relation between the continuous measure of effort-reward imbalance at work and self rated health. The associations persisted after adjusting for sociodemographic and socioeconomic conditions and, overall, the effect of these characteristics on self reported health did not seem to be mediated by socioeconomic status. The fact that the associations were similar in the five population samples and in both genders supports the robustness of findings. Whereas associations of distinct sociodemographic, socioeconomic and psychosocial (for example, perceived general control) conditions with self reported health have been reported previously, ${ }^{8-10}{ }^{18}$ no investigation to date, to our knowledge, explored the contribution of adverse psychosocial work environments, in explaining poor self rated health. According to the theoretical assumptions, the risk of experiencing poor subjective health was higher the higher the imbalance between efforts and rewards. ${ }^{15}$ With respect to the demandsupport-control model of job strain, no significant interaction terms were observed, in contrast with the theory ${ }^{14}$; only job variety and job control were consistently associated with self rated health. 
The finding of an adverse effect on health produced by effort-reward imbalance is consistent with an increasing body of evidence derived from prospective and cross sectional studies (for overview see Siegrist ${ }^{22}{ }^{29}$ ). However, firm conclusions concerning its possible causal effect cannot be drawn, because of the limitations of the cross sectional design. Firstly, some people may have taken worse jobs (with less favourable psychosocial conditions) because they were less healthy (reverse causation, selection bias). This possibility could only be excluded in a prospective study, but previous studies of social variation in health found little evidence for selection bias. ${ }^{30}$ Secondly, the perception of self rated health is subjective and can be influenced by other factors, including social and working circumstances (reporting bias). People suffering from poor health may respond differently to questions measuring effort and reward at work, although we excluded the impaired or chronically ill people and those on long term sick leave. Both biases would result in overestimation of the effects of work related factors. However, controlling for perceived control (which contained three questions on health locus of control and would therefore reflect differential reporting) did not remove the effects of psychosocial factors at work. This does not indicate a presence of a major bias.

In addition to the cross sectional design, several further limitations of this study need to be considered. Firstly, by dichotomising the outcome (self rated health), we may lose some information. However, there is good reason to concentrate on a high risk group as previous studies documented adverse effects of subjective health on measures of morbidity and mortality. ${ }^{135}$ Moreover, others have shown that self rated health is a continuous measure, and results on the dichotomised measure agree well with continuous answers. ${ }^{31}$ Secondly, the majority of information obtained from this study was collected by postal questionnaire, a research method susceptible to several sources of bias and error. However, in one population (Hungary), questions were answered in a standardised personal interview. The fact that neither the distribution of answers nor the observed odds ratios of the predicting variables differed significantly according to data collection method may reduce the methodological concern to some extent. The third limitation concerns the sample selection, and sampling and overrepresentation of urban populations, with higher than average education and, probably, more favourable working conditions. Thus the findings may not be directly generalisable to the whole population, although it is unlikely that the association between self rated health and work related factors would be biased.

This study is the first large scale investigation on associations of self reported health with adverse psychosocial work characteristics in working populations of post-communist societies. It confirmed that the relation between a stressful psychosocial work environment in terms of effort-reward imbalance and poor subjective health is not restricted to modern
Western societies but applies equally to Central and Eastern European societies that are currently subject to rapid socioeconomic transformation. It could be speculated that effort/ reward imbalance may be particularly stressful in a society in transformation, when many share the view that a privileged minority accumulates fortune without any obvious efforts and disregarding the fundamental principle of distributive justice.

In our analyses, job strain and its components (job demand and decision authority/job control) did not predict poor health that well. This may partly be attributable to measurement error. The original questionnaire contains three questions on job demand, but we only had one. Similarly, we used only four questions on decision authority, while the original questionnaire has eight questions. This might have led to imprecise measurement of these variables (random misclassification), which would bias the odds ratios towards unity. The larger number of questions on effort and reward, by contrast, could produce a relatively more precise measurement that would lead to apparently larger effects of the effort/reward ratio. On the other hand, when we combined decision latitude and job variety into job control, ${ }^{27}$ the effect of this combined variable was not stronger than those of the individual components. In general, however, although the effects of job demand were inconsistent in several studies on coronary heart disease, ${ }^{32}{ }^{33}$ we remain cautious in judging the merits of the two models with respect to self rated health.

The results on the possible interactions between variables are interesting for several reasons. Firstly, there were no interactions between job control, job demand and social support at work. Although such interactions have been observed in several studies, ${ }^{14} 192034$ they were not found in other studies, ${ }^{24}{ }^{32-37}$ and it is increasingly recognised that job control is the more important dimension of the model. ${ }^{38}$ Secondly, it has been often speculated that job related "stress" would be more harmful in lower socioeconomic groups. Our data do not support this view. Low job variety and low social support at work were related to increased risk of poor health in married subject, who are not disadvantaged or isolated. Similarly, the effects of job demand was more pronounced among subjects with better education. Both is the opposite than the anecdotal accounts.

An important methodological finding of this study relates to the effort-reward imbalance. Instead of the previously used binary measure, we applied a continuous indicator, the logarithmically transformed ratio of the effort and reward scores. This continuous measure is interesting for two reasons. Firstly, and most important, it is statistically more efficient, as it makes use of all original values in the data, rather than reducing the responses to two categories. Secondly, this measure can be used in populations with low prevalence of exposure to effort-reward imbalance, defined by the binary indicator. Other studies should validate the continuous measure in different populations. 
In conclusion, despite the limitations mentioned, this study reports consistent associations of adverse psychosocial characteristics with poor self rated health in economically active populations from Central and Eastern Europe. In particular, the model of effortreward imbalance seems a good predictor of poor self rated health. If confirmed by further evidence these findings provide an important contribution to our understanding of the poor health status of populations in Central and Eastern Europe.

Funding: this study was supported by grants from the EU Copernicus Programme and the John D and Catherine T MacArthur Foundation. MM is recipient of an MRC Research Professorship.

Conflicts of interests: none.

\section{Appendix 1 Definition of work psychosocial characteristics}

EFFORT AT WORK

(Q1) There is constant time pressure in my job due to a heavy workload

(Q2) There are many interruptions and disturbances in my job

(Q3) I have a lot of responsibility in my job

(Q4) There is pressure in my job to work overtime

(Q5) My job is physically demanding

(Q6) Over the past few years, my job has become more and more demanding

REWARD AT WORK

(Q1) Are you treated unfairly at work?

(Q2) Are the promotion prospects in your job poor?

(Q3) Have you experienced or do you expect to experience an undesirable change in your work situation?

(Q4) Have job redundancies recently affected your work colleagues?

(Q5) Is your own job security poor?

(Q6) Considering all your efforts and achievements, are your work prospects poor?

(Q7) Do you receive the respect you deserve from your work colleagues?

(Q8) Do you experience adequate support in difficult situations?

(Q9) Does your current job adequately reflect your knowledge, skills and training?

(Q10) Does your salary/income adequately reflect all your past efforts and achievements?

(Q11) Considering all your efforts and achievements, do you receive the respect and prestige you deserve at work?

OB DEMAND

(Q1) Do you have to work very intensively?

JOB DECISION AUTHORITY

(Q1) Do you have a choice in deciding HOW you do your work?

(Q2) Do you have a choice in deciding WHAT you do at work?

(Q3) Do you have a good deal of say in decisions about work?

(Q4) Do you have a great deal of say in planning your work environment?

SOCIAL SUPPORT AT WORK

(Q1) How often do you get help and support from your colleagues?

(Q2) How often are your colleagues willing to listen to your work related problems?

(Q3) How often do you get help and support from your immediate superior?

(Q4) How often is your immediate superior willing to listen to your problems?

JOB VARIETY

(Q1) Do you have the possibility of learning new things through your work?

(Q2) Does your work demand a high level of skill or expertise?

(Q3) Does your job require you to take the initiative?

Q4) Does your job provide you with a variety of interesting things to do?

1 Mossey JM, Shapiro E. Self-rated health: a predictor of mortality among the elderly. Am $f$ Public Health $1982 ; 72: 800-8$

2 Pijls LT, Feskens EJ, Kromhout D. Self-rated health, mortality, and chronic diseases in elderly men. The Zutphen Study, 1985-1990. Am f Epidemiol 1993;138: 840-8.

3 Idler EL, Benyamini Y. Self-rated health and mortality: a review of twenty-seven community studies. $\mathcal{F}$ Health Soc Behav 1997;38:21-37.

4 Miilunpalo S, Vuori I, Oja P, et al. Self-rated health status as a health measure: the predictive value of self-reported health status on the use of physician services and on mortality in the working-age population. F Clin Epidemiol 1997; 50:517-28.

5 Leung K-K, Tang L-Y, Lue B-H. Self-rated health and mortality in Chinese institutional elderly persons. 7 Clin Epidemiol 1997;50:1107-16.

6 Johnson RJ, Wolinski FD. The structure of health status among older adults: disease, disability, functional limitation, and perceived health. F Health Soc Behav 1993;34: 105-21

7 Hraba J, Lorenz F, Lee G, et al. Gender differences in health: evidence from the Czech Republic. Soc Sci Med 1996;43:1443-51.

8 Lahelma E, Martikainen P, Rahkonen O, et al. Gender differences in illhealth in Finland: patterns, magnitude and change. Soc Sci Med 1998;48:7-19.

9 Litwin H. Social network type and health status in a national sample of elderly Israelis. Soc Sci Med 1998;46:599-609.

10 Carlson P. Self-perceived health in East and West Europe: another European health divide. Soc Sci Med 1998;46: 1355-66.

11 Lachman ME, Weaver SL. The sense of control as a moderator of social class differences in health and well being. F Pers Soc Psychol 1998;74:763-73.

12 Kohn M, Schooler C. Work and personality: an inquiry into the impact of social stratification. Norwood, NJ: Ablex, 1983.

13 Cooper CL, ed. Theories of organizational stress. Oxford: Oxford University Press, 1998

14 Karasek RE, Theorell T. Healthy work: stress, productivity, and the reconstruction of working life. New York: Basic Books, 1990

15 Siegrist J. Adverse health effects of high-effort/low-effort conditions. F Occup Health Psychol 1996:1:27-41.

16 Bobak M, Marmot M. East-west mortality divide and its potential explanations: proposed research agenda. BMF 1996;312:421-5.

17 UNICEF International Child Development Centre. Education for all? Regional monitoring report no5. Florence: 1998.

18 Bobak M, Pikhart H, Rose R, et al. Socioeconomic factors, material inequalities, and perceived control in self-rated health: cross-sectional data from seven post-communist countries. Soc Sci Med 2000;51:1343-50.

19 Karasek RA. Job demands, job decision latitude, and mental strain: Implications for job redesign. Administrative Science Ouarterly 1979;24:285-307.

20 Johnson JV, Hall EM. Job strain, work place social support, and cardiovascular disease: a cross-sectional study of a ran-
dom sample of the Swedish working population. Am f Public Health 1988;78:1336-42.

21 Siegrist J. Threat to social status and cardiovascular risk. Psychother Psychosom 1984;42:90-6.

22 Siegrist J. Adverse health effects of effort-reward imbalance at work: theory, empirical support, and implications for prevention. In: Cooper CL, ed. Theories of organizational stress. Oxford: Oxford University Press, 1998:190-204.

23 Theorell T, Karasek RA. Current issues relating to psychosocial job strain and cardiovascular disease research. $f$ Occup Health Psychol 1996;1:9-26.

24 Bosma H, Peter R, Siegrist J, et al. Two alternative job stress models and the risk of coronary heart disease: the effort-reward imbalance model and the job strain model. Am 7 Public Health 1998;88:68-74.

25 Stansfeld SA, Fuhrer R, Shipley MJ, et al. Work characteristics predict psychiatric disorder: prospective results from tics predict psychiatric disorder: prospective results from
the Whitehall II study. Occup Environ Med 1999;56:302-7.

26 Principle investigators. The MONICA Project. A worldwide monitoring system for cardiovascular diseases. World Health monitoring system for car

27 Bosma H, Marmot MG, Hemingway H, et al. Low job conrol and risk of coronary heart disease in Whitehall II (prospective cohort) study. BMF 1997;314:558-65

28 Bobak M, Hertzman C, Skodova Z, et al. Socioeconomic status and cardiovascular risk factors in the Czech Republic. Int f Epidemiol 1999;28:46-52.

29 Siegrist J. A theory of occupational stress. In: Dunham J, ed. Stress in occupations: past, present and future. London: Whurr Publishers, 2000:63-6.

30 Blane D, Bartley M, Davey Smith G. Disease aetiology and materialist explanations of socioeconomic mortality differentials. Eur f Public Health 1997;7:385-91.

31 Manderbacka K, Lahelma E, Martikainen P. Examining the continuity of self-rated health. Int 7 Epidemiol 1998;27: 208-13. 
32 Marmot M.G, Bosma H, Hemingway H, et al. Contribution of job control and other risk factors to social variations in of job control and other risk factors to social variations in coronary

33 Bobak M, Hertzman C, Skodova Z, et al. Association between psychosocial factors at work and nonfatal myocardial infarction in a population-based case-control study in Czech men. Epidemiology 1998;9:43-7.

34 Hallqvist J, Diderichsen F, Theorell T, et al. Is the effect of job strain on myocardial infarction risk due to interaction between high psychological demands and low decision latitude? Results from Stockholm Heart Epidemiology Program (SHEEP). Soc Sci Med 1998;46:1405-15.
35 Schnall PL, Landsbergis PA, Baker D. Job strain and cardiovascular disease. Annu Rev Public Health 1994;15:381-411. vascular disease. Annu Rev Public Health 1994;15:381-411. 6 Pieper C, LaCroix AZ, Karasek RA. The relation of psycho-
social dimensions of work with coronary heart disease risk factors: a meta analysis of five United States databases. $\mathrm{Am}$ 7 Epidemiol 1989;129:483-94.

37 Johnson JV, Stewart W, Hall EM, et al. Long-term psychosocial work environment and cardiovascular mortality among Swedish men. Am F Public Health 1996;86:324-31.

38 Hemingway H, Marmot M. Evidence based cardiology: psychosocial factors in the aetiology and prognosis of coronary heart disease. Systematic review of prospective cohort studies. BMF 1999;318:1460-7.

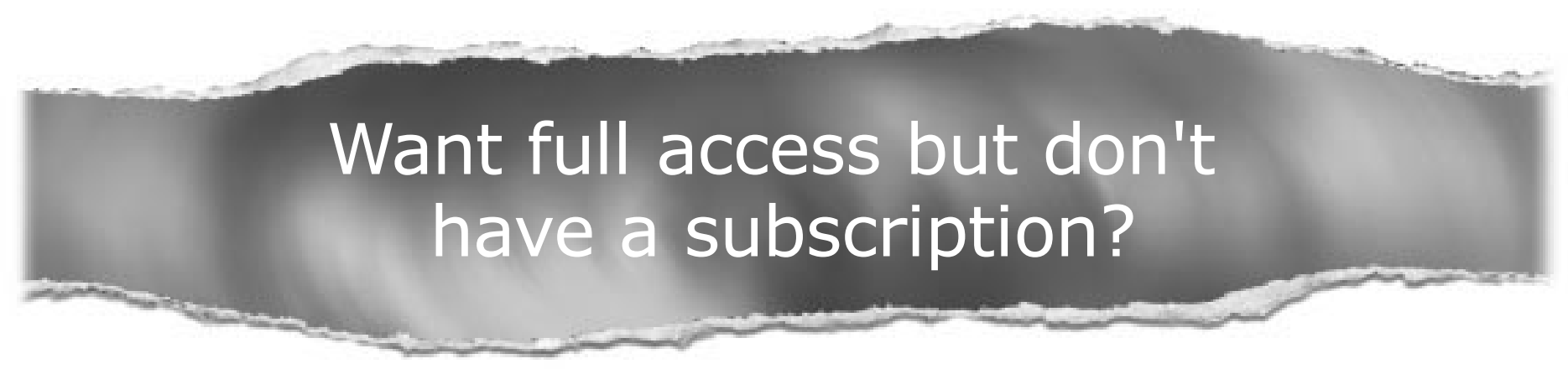

\section{Pay per access}

For just US $\$ 25$ you can have instant access to the whole website for 30 days. During this time you will be able to access the full text for all issues (including supplements) available. You will also be able to download and print any relevant pdf files for personal use, and take advantage of all the special features Journal of Epidemiology and Community Health online has to offer.

\section{www.jech.com}

